
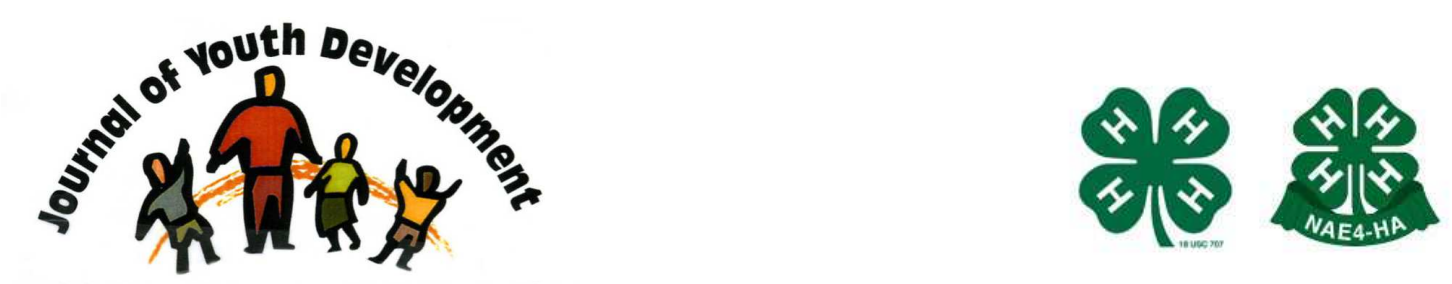

Bridging Research \& Practice

\title{
The Perfect Mindstorm: 4-H Robotics in Afterschool Settings
}

\author{
Dave Francis \\ Utah State University \\ Ogden, Utah \\ dave.francis@usu.edu \\ Deb Jones \\ Utah State University \\ Logan, Utah \\ deb.jones@usu.edu
}




\title{
JOURNAL OF YOUTH DEVELOPMENT \\ bridging research and practice

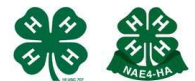

Volume 4, Number 4, Winter 2009

Article 090404PA002

\section{The Perfect Mindstorm: 4-H Robotics in Afterschool Settings}

Dave Francis and Deb Jones

Utah State University

\begin{abstract}
As the 4-H Science, Engineering and Technology (SET) Mission Mandate unfolds, robotics provides an opportunity to involve youth in SET activities. Utah 4-H utilized Lego Mindstorms Robotics kits to teach youth about robotics. Evaluations demonstrated that robots increase youth's interest in science, engineering and technology.
\end{abstract}

\section{Introduction}

4-H youth have been engaged in university-based research and demonstration projects for over 100 years - helping bring innovation and understanding to local communities. While many youth and adults think of 4-H as "cows and cookies," the organization has excellent resources and capacity to involve youth in non-formal science, engineering and technology (SET) experiences.

The importance of involving youth in the work of the land grant is as relevant today as it was 100 years ago. National trends demonstrate that youth are not adequately prepared for and pursuing education and careers in SET (NAEP, 2005). American students' low proficiency in math and science are a real concern in a world where advanced knowledge is widespread and low-cost labor is readily available. In addition, research indicates that the United States is producing fewer science and technology workers (Porter \& van Opstal, 2001).

Utah State University Extension 4-H provides SET experiences that go beyond teaching scientific principles. By integrating the 4-H program with strategies that support the developmental needs of young people, participants develop SET abilities and basic life skills as they experience teamwork and joint decision-making. Combining the outcomes of positive youth development with critical science, engineering and technology skills helps youth become prepared for careers in SET.

Through activities and projects, 4-H youth gain leadership, citizenship and life skills. These skills prepare young people to become effective in the workplace as well as in their communities. To 
be literate in the 21st Century means not just acquiring technology skills, but also the analytic, communications, interpersonal and self-directional skills, which 4-H programs provide. 4-H activities encourage youth to work together in large group activities that foster communication, teamwork and problem solving skills (National 4-H Council, 2008).

\section{The Need for SET}

Local requests encouraged Utah 4-H to increase the amount of SET training and programming for youth. Based on input from field staff and afterschool providers, the need was recognized to identify a program that would:

- Address topics in science, engineering and technology (SET)

- Be age appropriate for upper elementary and middle school youth

- Be fun and provide opportunities for hands on learning

- While not "boy specific," be something that would help attract boys to be involved in the program

After researching 4-H programs, Utah 4-H determined that the Lego Mindstorms Robotics program met these criteria. In addition to fulfilling the above criteria, Robotics also allows for several teaching components. Strong emotional appeal in building and programming robots, a competitive element that allowed youth to build and program robots to complete challenges and the possibility for a robots experience to be as short as 5 hrs or extend to 30 to 40 were attractive elements. Utah 4-H also began the program because of news of an upcoming 4-H Robotics curriculum and nationwide involvement of $4-\mathrm{H}$ in robotics.

\section{Getting started - Summer Camps}

To begin the Robotics program, Utah 4-H purchased four Lego Team Challenge Robotics sets. Each set contained over 800 Lego pieces, a programmable brick and the software. Ideal conditions allowed pairs of youth to share a computer and robotics set. The program was promoted to Utah 4-H field staff throughout state and they were able to checkout Robotics kits.

The Utah program quickly hit two barriers. Not every site had access to a computer lab and four kits were not sufficient to accommodate larger afterschool programs or a summer camp setting. In 2005 the program secured funds to purchase 12 robotics kits and 12 laptop computers. Five pilot programs were identified to complete a Robotics Camp "PROBE" that allows kids to build robots to work on a fictional planet -- Orange Planet H-99. The camp was based on a prepackaged "camp on a disk" from Lego Education that includes a CD-ROM with all of the information and curriculum to operate a robotics camp, including a camp itinerary, forms, posters, robot building instructions, animated slide shows, challenges, robot building and programming assistance.

Ninety-seven youth participated in five different summer camp experiences in 2006. All but one of the experiences were week-long for at least five hours a day. Evaluations mailed to camp participants yielded approximately a $30 \%$ return rate. Camp participants rated the quality of the camps' fun and educational aspects as 4.63 using the following scale: $1=$ poor; 2 =below average; 3=average; 4=above average; and 5=excellent. While our target grade was 6-8 camp sites reported upper elementary, grades 4-5 with some high school youth assisting in a counselor role. Gender information was not collected on camp participants but field staff expressed that a large majority of the campers were male. 
Seventy-four percent indicated an increased ability to work with others, with an average rating of 3.61. Participants shared:

"I had to work with other ideas as well as mine."

"I made new friends and we learned to work together and listen to each other to build our robot."

"One teammate would know more about handling computers or building strong structures, and the other teammate might know more about the other. This would help people to create a good program and robot."

"Me and another kid were teamed up for a competition so we started giving each other ideas and it got easier to work with other kids."

Seventy-five percent increased their ability to problem solve with an average rating of 3.72. Participants stated:

"When our robot wouldn't work we had to verbalize our thoughts as to what went wrong so we could fix it."

"Programming was challenging and I learned some new things from that."

"It took many tries but was rewarding in the end because if it didn't work right I had to figure out what was wrong."

An evaluation question asked parents how they felt their child benefited from the program. Parents said:

"Coby learned more about technology. He learned about programming. He learned about success and failure. He learned to work as a team."

"Tanner told me he wants to build robots for the moon, to repair the ozone layer, to reduce death in war and to make his bed in the morning. He was still learning even though school was out and realized how much fun math and science can be."

\section{Summer Camps - Year Two}

Based on the outcomes of the pilot summer camps and word-of-mouth spreading about the robotics activities, Utah 4-H saw an increase in the number of requests of afterschool programs. These programs were able to utilize the same activities, but spread the lessons out over a longer period.

In 2007, Utah 4-H saw an increase in the number of requests to complete a summer robotics experience. Many field staff utilized Robotics summer camps in order to introduce the 4-H experience to the community and then followed the camp up with a longer term after school camp or 4-H club setting. With increased kits, the Robotics program reached over 160 youth. To accommodate the sites from the previous year the theme changed to "Aquabots: Voyage to Sealab Nautilus." The materials provided similar activities to PROBE with an ocean exploration theme including building robots to explore the ocean floor and saving a giant squid. 
Evaluations mailed to 2007 camp participants yielded approximately a $40 \%$ return rate. Camp quality was similar to the previous year overall, rated 4.69 compared to 4.63; increase in the ability to work with others was rated 4.0, compared to 3.61 ; and problem solving was rated 4.0 compared to 3.72 .

Eighty-two percent indicated that the experience made them more interested in exploring career possibilities in SET. In response to the question, "Did your experience with the 4-H robotics program make you more interested in exploring career possibilities in science, engineering, or technology," participants stated:

"By showing us the capability of the robots and technology."

"I got to learn how to program robots and learn about them."

"I was planning on getting a science or technology career and this boosted my want for a job like those."

"Because the whole robotics thing was fascinating and fun."

\section{Equipment and Resources}

Purchase, transport and storage of all of the robotic equipment is an ongoing project. Funds to continue the program were identified through various internal and external sources. Utah 4-H found it easier to secure funding by linking life skills and SET literacy gained through the robotics experience to SET career awareness and economic development. To improve programs around the state, robotics kits are placed regionally to allow easier pick up and return. Four kits are stored in a large plastic tote with the entire support software and design book in a binder with each book and kit assigned a number. Totes make it easier to store and transport from car to building and they can be shipped through the mail to assist more remote locations. During the summer months, kits can be checked out for one week and during the rest of the year kits can be checked out on a one to two month basis. As word spread about the program, Utah 4-H saw an increase in afterschool sites purchasing their own equipment either to use for an extensive program or to rotate within various sites within a school district.

\section{Training}

From the start, Utah 4-H recognized that facilitators of the robotics experience may not be as "tech savvy" and may feel intimidated by the program. However, we encouraged staff to learn with the youth and not feel like that had to know all of the answers. Staff training took on many forms including self-guided experiences to all day training events. Shorter trainings provided simple hands-on experiences and an overview of the program. Longer trainings allowed participants to spend time building and programming robots and utilizing the challenge board. Included on the Robolab software is a series of systematic tutorials with audio and video to allow learners to go at their own pace. An additional feature of the Camp on a Disk program was the ability to see the robots building instructions as a piece-by-piece screen shot, video clips of the robot in action and sample program outlines to edit and change. As the program continues to grow Utah 4-H is beginning to see a community of practice develop that shares ideas and support. An example of the Robotics Club setup, developed by one of the volunteers, can be found at www.utah4-h.org. 


\section{The Experience - Expanding Our Outreach}

While the bulk of robotics camp experiences utilized a summer day camp format, other delivery modes have also been applied including:

- A short-term after school program that provides robotics for the duration of a quarter or semester during afterschool times

- A longer term project as part of a youth mentoring program that allowed youth and their mentors to work on robotics projects together

- An ongoing 4-H club that meets twice a month

- An all day Saturday program

Regardless of the format, Utah 4-H found the robotics experience created positive and memorable experiences for youth. When asked, "What was your favorite thing to learn about in this program," often participants cited specific team challenges and how they completed the task. One camp participant responded, "The mission where we had to take the squid to the cave, it was fun and challenging."

Utah 4-H has identified that robotics and specifically the Lego Mindstorms are an effective tool to engage kids in SET when they are not in school. Camp evaluation results indicate that robotics increases skills in SET abilities and encourages kids to think about careers in SET. To reach more youth, Utah 4-H is working with afterschool partners through the statewide afterschool network to increase awareness and training in robotics.

\section{Replication}

For groups wanting to start a robotics program funding is often the greatest obstacle. During the Utah 4-H experience, state government, technology-focused businesses and foundations were interested in funding career exploration specifically for SET at the middle school and high school level. Once started, depending on the geographic location and local market, robotics programs were unique enough to generate camp fees upwards of $\$ 179$ per child for a $30 \mathrm{hr}$. a week camp experience. These funds helped purchase additional materials to support the program and provided fee waivers for underserved audiences. Camps also provided a core group of interested youth that formed longer term 4-H clubs. These clubs were able to purchase parts from www.ebay.com to assemble kits at a cheaper rate.

To find out more about 4-H Science, Engineering and Technology programs visit www.national4hcouncil.edu 


\section{References}

National Assessment of Education Progress. (2005). The Nation's Report Card. National Center for Education Statistics, Institute of education Sciences, U.S. Department of Education, Washington D.C. Available from http://nces.ed.gov/nationsreportcard/subjectareas.asp

Porter, M., \& van Opstal, D. (2001). U.S. competitiveness 2001: Strengths vulnerabilities and long-term priorities. Washington, DC: Council on Competitiveness.

(C) Copyright of Journal of Youth Development Bridging Research and Practice. Content may not be copied or emailed to multiple sites or posted to a listserv without copyright holder's express written permission. However, users may print, download or email articles for individual use. 